ORIGINAL ARTICLE

\title{
Does the use of $50 \%$ oxygen at birth in preterm infants reduce lung injury?
}

\author{
A E Harling, M W Beresford, G S Vince, M Bates, C W Yoxall
}

See end of article for authors' affiliations

Correspondence to: Miss Harling, Neonatal Intensive Care Unit, Liverpool Women's Hospital, Crown Street, Liverpool L8 7SS, UK Elizabeth.Harling@|wh-tr. nwest.nhs.uk

Accepted 18 March 2005 Published Online First 29 April 2005

Background: Bronchopulmonary dysplasia is an inflammatory fibrotic condition produced as a consequence of injurious influences in the neonatal lung. Exposing the premature lung to high concentrations of oxygen is thought to play an important part in lung injury pathogenesis.

Objective: To see if the amount of oxygen used during resuscitation at birth triggers events that lead to the subsequent lung injury and if a reduction in oxygen used leads to a reduction in lung injury.

Method: The outcomes of newborn babies less than 31 weeks gestation who were resuscitated using either $50 \%$ or $100 \%$ oxygen were examined. Eight of the babies receiving $50 \%$ oxygen required an increase in their oxygen concentration. Evidence of pulmonary inflammation was determined by quantifying interleukin $6,1 \beta$, and 10 and tumour necrosis factor $\alpha$ in bronchoalveolar lavage fluid by enzyme linked immunosorbent assay.

Results: There were no significant differences in any of the cytokines studied in either of the groups. Death occurred in 5/26 (19\%) babies who received 100\% oxygen and $4 / 26(15 \%)$ babies who received $50 \%$ oxygen. Survival without bronchopulmonary dysplasia at 36 weeks postmenstrual age occurred in 14/26 $(54 \%)$ and $13 / 26(50 \%)$.

Conclusion: Reducing the oxygen to $50 \%$ at resuscitation did not influence either short or long term outcomes, but a small benefit could not be excluded. There was no increase in adverse clinical outcomes in babies who received $100 \%$ oxygen.

$\mathrm{B}$ ronchopulmonary dysplasia (BPD) is an inflammatory fibrotic condition produced as a consequence of injurious influences in the neonatal lung. The process of inflammation within the premature lung is a host response to several injurious insults such as volutrauma, infection, and oxygen toxicity. Exposure to high concentrations of oxygen is thought to play a significant part in the pathogenesis of lung injury, through damage caused by toxic reactive oxygen species (ROS) or oxygen free radicals. ${ }^{12}$ ROS are derived from sequential incomplete reduction of oxygen within the cell and can damage lipids, carbohydrate, and proteins causing enzyme dysfunction and loss of integrity of cellular and organelle membranes, with resulting cellular dysfunction. ${ }^{34}$

ROS have also been shown to damage genetic material and are known to activate nuclear factor $\kappa \mathrm{B}$, which enhances the expression of many cytokine genes involved in inflammation. ${ }^{56}$

Pulmonary inflammation is a complex cascade of events in which cytokines are responsible for both the promotion and modulation of the inflammatory process. Several cytokines have been found to be prominent in the early stages of this inflammatory process in the ventilated premature baby. ${ }^{7-14}$

It is possible that the use of $100 \%$ oxygen during resuscitation at birth is responsible for initiating the process that ultimately leads to lung damage, and using less oxygen at resuscitation may ameliorate the problem in preterm babies.

There is evidence from research conducted with term, asphyxiated babies that they can be as effectively resuscitated in air as with $100 \%$ oxygen, with no apparent difference in long term outcomes. ${ }^{15-18}$ There are, however, no studies in preterm infants that have looked at the outcome of this intervention on lung injury.

The aim of this study was to investigate whether lung injury could be reduced in very premature babies by using $50 \%$ as opposed to $100 \%$ oxygen during resuscitation at birth.
Table 1 Basic and clinical details of babies receiving $50 \%$ or $100 \%$ oxygen, and cytokine concentrations at 0 hours in both oxygen groups

\begin{tabular}{|c|c|c|}
\hline & $50 \% \mathrm{O}_{2}(n=26)$ & $100 \% O_{2}(n=26)$ \\
\hline Birth weight $(\mathrm{g})$ & $1010(518-1528)$ & $973(560-1562)$ \\
\hline Gestation (weeks) & $27(23-31)$ & $28(24-30)$ \\
\hline $\operatorname{Sex}(F / M)$ & $11 / 15$ & $13 / 13$ \\
\hline Apgar at $1 \mathrm{~min}$ & $5(2-9)$ & $6.5(1-10)$ \\
\hline Apgar at $5 \mathrm{~min}$ & $8(3-10)$ & $8(3-10)$ \\
\hline PROM (hours) & $0(0-1221)$ & $0(0-183)$ \\
\hline Caesarean section & 10 & 13 \\
\hline $\begin{array}{l}\text { Clinical evidence of } \\
\text { chorioamnionitis }\end{array}$ & 8 & 8 \\
\hline Antenatal steroids (doses) & $2(1-9)$ & $2(1-9)$ \\
\hline Time to intubation (min) & $4(1-15)$ & $5(2-20)$ \\
\hline Time to surfactant (min) & $12(3-59)$ & $15(5-46)$ \\
\hline Cord $\mathrm{pH}$ & $7.32(6.95-7.44)$ & $7.31(7.00-7.44)$ \\
\hline $\begin{array}{l}\text { Positive blood culture } \\
\text { (taken at birth) }\end{array}$ & 0 & 0 \\
\hline IL6 at $0 \mathrm{~h}(\mathrm{pg} / \mathrm{ml})$ & $\begin{array}{l}537(0-17269) \\
(\mathrm{n}=18)\end{array}$ & $\begin{array}{l}790(16-29205) \\
(n=16)\end{array}$ \\
\hline IL1 $\beta$ at $0 \mathrm{~h}(\mathrm{pg} / \mathrm{ml})$ & $\begin{array}{l}37(0-2950) \\
(\mathrm{n}=18)\end{array}$ & $\begin{array}{l}35(0-2637) \\
(n=16)\end{array}$ \\
\hline IL10 at $0 \mathrm{~h}(\mathrm{pg} / \mathrm{ml})$ & $\begin{array}{l}533(10-2330) \\
(\mathrm{n}=18)\end{array}$ & $\begin{array}{l}514(43-1485) \\
(n=16)\end{array}$ \\
\hline $\mathrm{TNF} \alpha$ at $\mathrm{Oh}(\mathrm{pg} / \mathrm{ml})$ & $\begin{array}{l}51(8-309) \\
(n=18)\end{array}$ & $\begin{array}{l}47(10-662) \\
(n=15)\end{array}$ \\
\hline
\end{tabular}

Data are expressed as median (range) or number.

PROM, Premature rupture of membranes; IL, interleukin; TNF $\alpha$, tumour necrosis factor $\alpha$.

Abbreviations: BAL, bronchoalveolar lavage; BPD, bronchopulmonary dysplasia; IL, interleukin; PIP, peak inspiratory pressure; ROS, reactive oxygen species; TNF $\alpha$, tumour necrosis factor $\alpha$ 


\section{METHODS}

This was a randomised controlled trial with factorial design. The interventions compared were the use of either $50 \%$ or $100 \%$ oxygen as a resuscitation gas at birth and the use of sustained lung inflation for five seconds before the onset of tidal ventilation compared with the currently used two to three seconds of inflation. Comparison of the two oxygen concentrations is presented here.

Block randomisation using sealed envelopes was used. Although consent was obtained earlier, randomisation did not take place until delivery of the baby was imminent.

The primary outcome measure of evidence of pulmonary inflammation was concentration of the cytokines interleukin (IL)6, IL10, IL1 $\beta$, and tumour necrosis factor $\alpha$ (TNF $\alpha)$ in bronchoalveolar lavage (BAL) fluid obtained at 12 hours of age. Secondary outcome measures included: the severity of initial lung disease determined by blood gas analyses, oxygen and ventilator requirements over the first 24 hours of postnatal life; death; BPD (oxygen requirement at 36 weeks postmenstrual age); major cranial ultrasound abnormality (post-haemorrhagic ventricular dilatation requiring treatment, parenchymal haemorrhage, or cystic periventricular leucomalacia); necrotising enterocolitis (pneumoperitoneum or pneumatosis on abdominal radiograph or confirmed at laparotomy or postmortem examination); retinopathy of prematurity leading to treatment in accordance with national guidelines ${ }^{19}$ or blindness; a patent ductus arteriosus requiring treatment; systemic infection proven by positive blood culture; pneumothorax requiring chest drain insertion.

\section{Subjects}

Babies born at less than 31 completed weeks gestation were eligible for recruitment into the study, but only those who required some degree of resuscitation at birth and had no life threatening malformations were included.

\section{Resuscitation}

The resuscitation was conducted on a Vickers Resuscitaire Radiant Warmer (Air-Shields; Hill-Rom, Leicester, UK). This provided the facility to deliver fractions of inspired oxygen and tidal ventilation. The oxygen was preset to be delivered at either $100 \%$ or $50 \%$ for the duration of the resuscitation until cardiorespiratory stability was achieved and surfactant had been given. It could then be altered at the discretion of the person conducting the resuscitation. Pulse oximetry was not used until the baby arrived on the neonatal unit. The peak inspiratory pressure (PIP) was set at $25-30 \mathrm{~cm} \mathrm{H}_{2} \mathrm{O}$, and the positive end expiratory pressure at $3-4 \mathrm{~cm} \mathrm{H}_{2} \mathrm{O}$.

The babies received tidal ventilation during transportation to the neonatal unit on the resuscitaire. At the neonatal unit, they were ventilated using conventional intermittent positive pressure on a time cycled pressure limited SLE 2000 baby ventilator (Specialist Laboratories Equipment, Croydon, Surrey, UK).

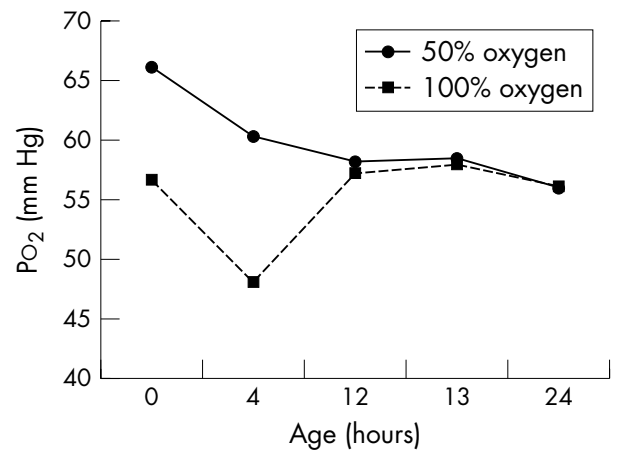

Figure 1 Median partial pressure of oxygen over first 24 hours in babies receiving $50 \%$ oxygen or $100 \%$ oxygen.

\section{BAL fluid}

BAL fluid was taken immediately after intubation and stabilisation of the baby at birth before the first dose of exogenous surfactant ( 0 hours), and the second at 12 hours of age before the second dose of surfactant ( 12 hours). One person $(\mathrm{AEH})$ performed BAL fluid collection using a standard technique. ${ }^{812} 20$

\section{Cytokine quantification}

Cytokines in BAL fluid supernatant were determined with a commercial enzyme linked immunosorbent assay (R\&D Systems Europe Ltd, Abingdon, Oxon, UK). The limits of detection for the individual assays were $6.2 \mathrm{pg} / \mathrm{ml}$ for IL6, $3.9 \mathrm{pg} / \mathrm{ml}$ for ILl $\beta, 62.4 \mathrm{pg} / \mathrm{ml}$ for IL10, and $15.6 \mathrm{pg} / \mathrm{ml}$ for $\mathrm{TNF} \alpha$. Standards and samples were run in duplicate, and the $\log$ of the mean absorbance was plotted. Regression analysis was used to determine the line of best fit from which the cytokine concentrations were read; an $r^{2}$ of 0.95 and above was considered acceptable. If a sample exceeded the upper

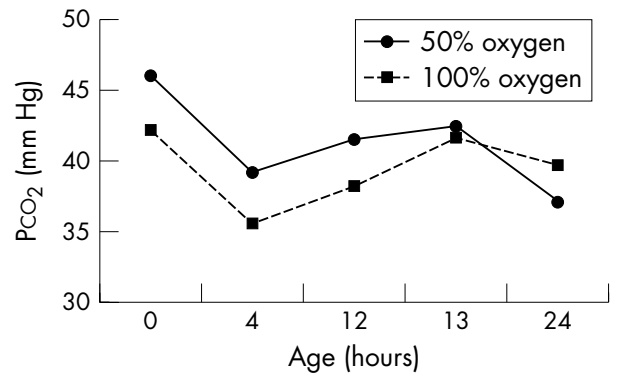

Figure 2 Median partial pressure of carbon dioxide over first 24 hours in babies receiving $50 \%$ oxygen or $100 \%$ oxygen.

Table 2 Cytokine concentrations at 12 hours in babies resuscitated in either $50 \%$ or $100 \%$ oxygen

\begin{tabular}{llll}
\hline Cytokine & $50 \% \mathrm{O}_{2}(\mathbf{n = 2 6 )}$ & $100 \% \mathrm{O}_{2}(\mathrm{n}=26)$ & $\mathrm{p}$ Value \\
\hline IL6 & $1125(104-15192)$ & $828(42-19708)$ & 0.69 \\
& $(n=22)$ & $(n=17)$ & \\
IL1 $\beta$ & $45(0-2590)$ & $29(5-575)$ & 0.42 \\
& $(n=22)$ & $5817)$ & \\
IL10 & $715(0-1993)$ & $(n=18)$ & 0.76 \\
TNF $\alpha$ & $(n=22)$ & $21(0-1838)$ & 0.75 \\
& $26(0-204)$ & $(n=16)$ & \\
\hline
\end{tabular}

Values are median (range) expressed as $\mathrm{pg} / \mathrm{ml}$ bronchoalveolar lavage fluid. IL, Interleukin; TNF $\alpha$, tumour necrosis factor $\alpha$. 


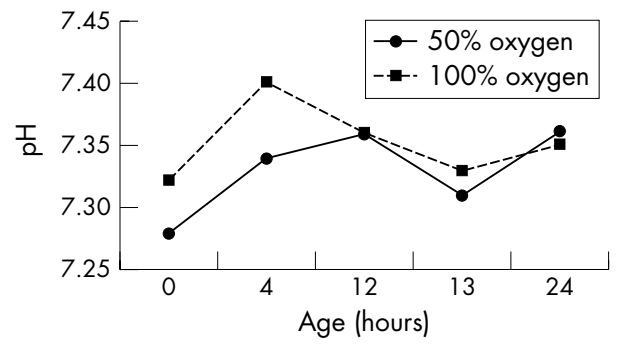

Figure 3 Median pH over first 24 hours in babies receiving 50\% oxygen or $100 \%$ oxygen.

limit of the assay, a second sample was diluted and assayed; the results were then multiplied by the dilution factor. The cytokine concentrations are expressed as $\mathrm{pg} / \mathrm{ml}$ BAL fluid in line with the current recommendations of the ERS task force. ${ }^{21}$

\section{Statistical analysis}

No previously published data were available from which to generate a sample size calculation. We planned a pilot study with a view to using any differences observed between the groups to calculate a sample size for a later definitive study. To show a difference of one standard deviation in any of the continuous variables, we planned to randomise 20 ventilated babies into each group. The Mann-Whitney U test was used for the continuous data, and the $\chi^{2}$ test for categorical data. Two tailed tests were used for all statistical comparisons, and $\mathrm{p}<0.05$ was considered significant. Statistical analyses were performed using SPSS for Windows 10.0.7. (SPSS, Chicago, Illinois, USA).

\section{Ethical considerations}

Informed parental consent was obtained in the antenatal period, and the study had the approval of the local paediatric research ethics committee.

\section{RESULTS}

A total of 63 babies were randomised into the study. Fifty two required resuscitation and received the intervention. However, eight of the babies randomised to receive $50 \%$ oxygen required a brief increase beyond $50 \%$. Ten babies responded to resuscitation by face mask, and 42 proceeded to intubation. A further four babies were intubated on the neonatal unit. We studied the outcomes of all 52 babies who had received the intervention, although the primary outcome of BAL cytokine concentrations was not available for babies not intubated.

The antenatal history was similar in the two groups: all mothers had received antenatal steroids and all intubated babies received exogenous surfactant (table 1).

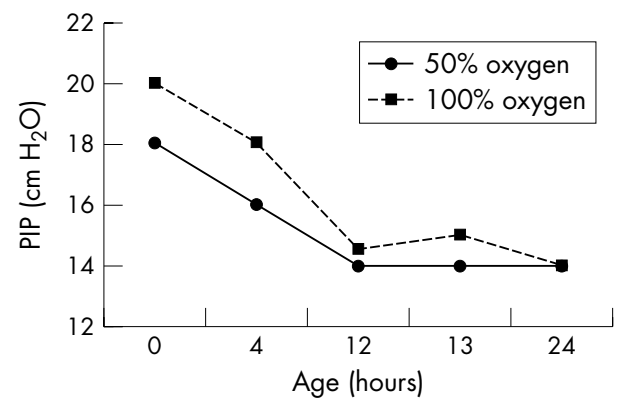

Figure 4 Median peak inspiratory pressure (PIP) over first 24 hours in babies receiving $50 \%$ oxygen or $100 \%$ oxygen.

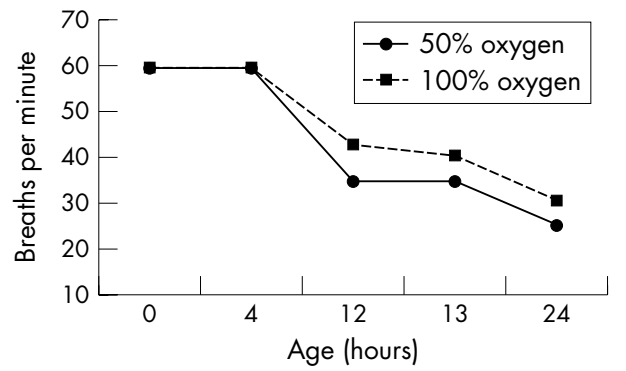

Figure 5 Median breaths per minute over first 24 hours in babies receiving $50 \%$ oxygen or $100 \%$ oxygen.

The median time to intubation was four minutes in the $50 \%$ oxygen group and five minutes in the $100 \%$ oxygen group. Surfactant was administered by a median time of 12 and 15 minutes respectively. The first BAL fluid was collected as soon as cardiorespiratory stability was achieved and immediately preceded the first dose of surfactant. Randomisation continued until there were sufficient babies intubated to measure the primary outcome of BAL inflammatory markers at 12 hours. Thirty four samples were suitable for analysis at 0 hours and 40 at 12 hours, although there was not sufficient volume of BAL fluid for all babies to permit analysis of all four cytokines at both time points. Table 1 shows the 0 hour BAL fluid cytokine concentrations.

\section{Cytokine concentrations}

The interassay coefficient of variation and intra-assay coefficient of repeatability for each cytokine were as follows: IL6, 5.98\% and $24.11 \%$; IL1 $\beta 1.76 \%$ and $19.80 \%$; IL10 $16.32 \%$ and $33.49 \%$; $\mathrm{TNF} \alpha 5.93 \%$ and $42 \%{ }^{22}$

We found all four cytokines studied present from immediately after birth and at 12 hours of age. However, not all the babies had detectable concentrations of all the cytokines at both time points. Table 2 shows the distribution of cytokine concentrations within the oxygen groups. There were no significant differences in any of the cytokine concentrations between the two groups.

\section{Ventilator requirements}

The only difference found was in the initial PIP, which was slightly higher in the $100 \%$ oxygen group immediately after birth $(\mathrm{p}=0.02)$. Otherwise oxygen and ventilator requirements and blood gas analyses were similar in the two groups for the first 24 hours of life. Figures 1-6 show the ventilation and blood gas median results; the ranges are omitted for clarity.

\section{Clinical outcomes}

Table 3 shows long term clinical outcomes. There were no significant differences between the groups.

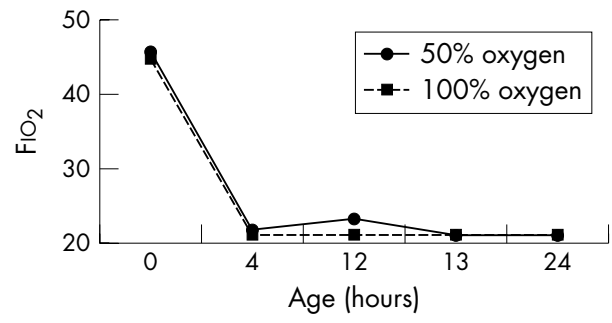

Figure 6 Median fraction of inspired oxygen $\left(\mathrm{FlO}_{2}\right)$ over first 24 hours in babies receiving $50 \%$ oxygen or $100 \%$ oxygen. 
Table 3 Long term clinical outcomes in babies resuscitated in either $50 \%$ or $100 \%$ oxygen

\begin{tabular}{llll}
\hline Outcome & $\begin{array}{l}50 \% \mathbf{O}_{2} \\
(\mathbf{n = 2 6 )}\end{array}$ & $\begin{array}{l}\mathbf{1 0 0 \%} \mathbf{O}_{\mathbf{2}} \\
(\mathbf{n = 2 6 )}\end{array}$ & $\mathbf{p}$ Value \\
\hline Died & 4 & 5 & 0.71 \\
Death from respiratory cause & 1 & 2 & 0.55 \\
Death or BPD at 36 weeks & 13 & 12 & 0.78 \\
Respiratory death or BPD at 36 weeks & 10 & 9 & 0.76 \\
BPD (oxygen therapy after 28 days) & 14 & 12 & 0.84 \\
BPD (oxygen therapy after 36 weeks) & 9 & 7 & 0.81 \\
Home in oxygen & 6 & 3 & 0.54 \\
Patent ductus arteriosus (treated) & 4 & 2 & 0.38 \\
Necrotising enterocolitis & 2 & 0 & 0.22 \\
Retinopathy of prematurity (treated/blind) & 0 & 0 & 0.55 \\
Pneumothorax & 1 & 2 & 0.63 \\
Abnormal cranial ultrasound & 3 & 2 & 0.54 \\
Positive blood culture episodes & 7 & 9 & \\
\hline BPD, Bronchopulmonary dysplasia. & & &
\end{tabular}

\section{DISCUSSION}

To our knowledge this is the first study to specifically address the question of whether the amount of oxygen used during the resuscitation of preterm babies affects lung injury. There was no evidence of any difference in lung injury between the two oxygen groups when they were assessed by the BAL fluid cytokine concentrations (table 2), neither did we show a difference in long term clinical outcomes (table 3 ). However, eight $(31 \%)$ of the babies from the $50 \%$ oxygen group who were difficult to intubate did experience an increase in oxygen concentration at some point during resuscitation, which may have weakened the power of this pilot study to detect a difference. This is a higher number than in a previous study in which babies were randomised to either air or $80 \%$ oxygen. Here $26 \%$ of the babies in the air group required more oxygen, but concentration did not exceed $50 \%{ }^{23}$

It may also be that the period of time over which we collected BAL fluid was too short. Had we collected daily sequential BAL fluid samples and for a longer time period, a difference in cytokine concentrations between the two groups may have been evident.

However, given the similarities in the initial course of the respiratory illness and eventual outcome in the two groups (table 3), we think it is unlikely that a reduction of inspired oxygen from $100 \%$ to $50 \%$ during resuscitation is of any benefit.

The only significant difference in blood gas measurements or oxygen or ventilator requirement between the two groups was in the initial PIP on admission to the neonatal unit: $20 \mathrm{v}$ $18 \mathrm{~cm} \mathrm{H}_{2} \mathrm{O}$ in the $100 \%$ and $50 \%$ oxygen groups respectively $(p=0.02$; fig 4). Clinical practice on our neonatal unit is to set the initial PIP between 18 and $20 \mathrm{~cm} \mathrm{H}_{2} \mathrm{O}$ for babies requiring ventilation because of prematurity until ventilator requirements are confirmed by blood gas analysis. The difference we observed between the two groups is probably a type 1 error.

The question as to whether preterm infants can be effectively resuscitated in less than $100 \%$ oxygen and whether using less oxygen would reduce the number of infants who develop BPD has yet to be answered. Current recommendations are still that $100 \%$ oxygen be used for resuscitation in this vulnerable group of infants. ${ }^{24}$ From our study we can only say that the use of $50 \%$ oxygen for resuscitation of premature babies appears to be safe, but there is no evidence of benefit, although we cannot exclude a small effect. A study of this size in which the prevalence of death or BPD in the control group was $46 \%$ would have only been able to detect a difference of $34 \%$ with a sensitivity of $5 \%$ and power of $80 \%$.

\section{What is already known on this topic}

- It is well documented that air is as effective as $100 \%$ oxygen when used to resuscitate term asphyxiated babies

- Preterm babies resuscitated with $80 \%$ oxygen or air have similar short term outcomes, including a persistent oxygen requirement at 28 days of life

\section{What this study adds}

- No short term benefit was shown from the use of $50 \%$ oxygen as apposed to $100 \%$ oxygen for resuscitation of the preterm baby at birth

- The use of $50 \%$ oxygen did not adversely affect outcome

\section{CONCLUSIONS}

Reducing the amount of oxygen from 100\% to 50\% for initial resuscitation in preterm babies appears to be safe, although we were unable to detect any difference in either short or long term outcomes, and there was no evidence of increased lung injury in the babies who received $100 \%$ oxygen.

\section{RECOMMENDATIONS}

Further studies comparing the effectiveness and safety of using lower oxygen concentrations during resuscitation are needed before a change in clinical practice can be recommended.

\section{Authors' affiliations}

A E Harling, M W Beresford, C W Yoxall, NICU, Liverpool Women's Hospital, Liverpool L8 7SS, UK

G S Vince, M Bates, Immunology Department, University of Liverpool, Liverpool L69 3GA

This research was supported by grants from The Smith \&Nephew Foundation, The North West R\&D Research Fellowship, and The Newborn Appeal.

Competing interests: none declared 


\section{REFERENCES}

1 Saugstad OD. Oxygen radicals and pulmonary damage. Pediatr Pulmonol 1985; 1:167-75.

2 Saugstad OD. Bronchopulmonary dysplasia and oxidative stress: are we closer to an understanding of the pathogenesis of BPD? Acta Pediatr 1997;86:1277-82.

3 Haddad IY, Zhu S, Tilden SJ, et al. Mechanisms and physiological sequelae of reactive species injury to the alveolar epithelium. In: Bland RD, Coalson JJ, eds. Chronic lung disease in early infancy. New York: Marcel Dekker, Inc, 2000:431-55.

4 Frank HL, Sosenko IRS. Oxidants and antioxidants: what role do they play in chronic lung disease. In: Bland RD, Coalson JJ, eds. Chronic lung disease in early infancy. New York: Marcel Dekker, Inc, 2000:841-58.

5 Baeuerle PA, Baltimore D. NF- $\kappa$ B: ten years after. Cell 1996;87:13-20.

6 Fan J, Ye RD, Malik AB. Transcriptional mechanisms of acute lung injury. Am J Physiol Lung Cell Mol Physiol 2001;281:L1037-50.

7 Bagchi A, Viscardi RM, Taciak V, et al. Increased activity of interleukin-6 but not tumour necrosis factor- $\alpha$ in lung lavage of premature babies is associated with the development of bronchopulmonary dysplasia. Pediatr Res 1994;36:244-51.

8 Kotecha S, Wilson L, Wangoo A, et al. Increase in interleukin (IL)- $1 \beta$ and IL-6 in bronchoalveolar lavage fluid obtained from babies with chronic lung disease of prematurity. Pediatr Res 1996;40:250-6.

9 Munshi UK, Niu JO, Siddiq MM, et al. Elevation of interleukin-8 and interleulin- 6 precedes the influx of neutrophils in tracheal aspirates from preterm babies who develop bronchopulmonary dysplasia. Pediatr Pulmonol 1997; 24:331-6.

10 Rindfleisch MS, Hasday JD, Taciak V, et al. Potential role of interleukin-1 in the development of bronchopulmonary dysplasia. J Interferon Cytokine Res 1996; 16:365-73.

11 Jones CA, Cayabyab RG, Kwong KYC, et al. Undetectable interleukin (IL)-10 and persistent IL-8 expression early in hyaline membrane disease : a possible developmental basis for the predisposition to chronic lung inflammation in preterm newborns. Pediatr Res 1996;39:966-75
12 McColm JR, Stenson BJ. Biermasz N, et al. Measurements of interleukin 10 in bronchoalveolar lavage from preterm ventilated babies. Arch Dis Child Fetal Neonatal Ed 2000;82:F156-9.

13 Jonsson B, Tullus K, Brauner A, et al. Early increase of TNF $\alpha$ and IL-6 in tracheobronchial aspirate fluid indicator of subsequent chronic lung disease in preterm babies. Arch Dis Child Fetal Neonatal Ed 1997;77:F198-201.

14 Beresford MW, Shaw NJ. Detectable IL-8 and IL-10 in bronchoalveolar lavage fluid from preterm babies ventilated for respiratory distress syndrome. Pediatr Res 2002;52:973-8.

15 Ramii S, Ahuja S, Thirupuram S, et al. Resuscitation of asphyxic newborn babies with room air or 100\% oxygen. Pediatr Res 1993;34:809-12.

16 Saugstad OD, Rootwelt T, Aalen O. Resuscitation of asphyxiated newborn babies with room air or oxygen: an international controlled trial: Resair 2 study. Pediatrics 1998;102(1). http//www.pediatrics.org/cgi/content/full/102/l/el.

17 Saugstad OD, Ramii S, Irani SF, et al. Resuscitation of newborn babies with $21 \%$ or $100 \%$ oxygen. Follow up at 18-24 months [abstract]. Pediatr Res 2002;52:819.

18 Vento M, Asensi M, Sastre J, et al. Resuscitation with room air instead of $100 \%$ oxygen prevents oxidative damage stress in moderately asphyixiated term neonates. Pediatrics 2001;107:642-7.

19 Royal College of Ophthalmologists, British Association of Perinatal Medicine. Retinopathy of prematurity: guidelines for screening. London: RCO/BAPM, 1995:1-15.

20 Placzek O, Silverman M. Selective placement of bronchial suction catheters in intubated neonates. Arch Dis Child 1983;58:829-30.

21 ERS Task Force. Bronchoalveolar lavage in children. Eur Respir J 2000;15:217-31.

22 Bland JM, Altman DG. Statistical methods for assessing agreement between two methods of clinical measurement. Lancet 1986;1:307-10.

23 Lundstrom KE, Pryds O, Greisen G. Oxygen at birth and prolonged cerebral vasoconstriction in preterm infants. Arch Dis Child Fetal Neonatal Ed 1995:73:F81-6.

24 Kattwinkel J, Niermeyer S, Nadkarni V, et al. An advisory statement from the pediatric working group of the International Liaison Committee on Resuscitation. Pediatrics 1999;103:e56. 